Article

\title{
Two-Step Elution Recovery of Cyanide Platinum Using Functional Metal Organic Resin
}

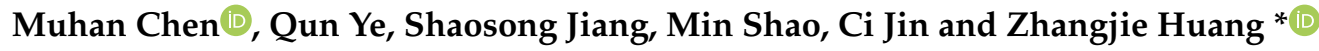 \\ School of Chemistry Science and Engineering, Yunnan University, Cuihu North Road No. 2, \\ Kunming 650091, China \\ * Correspondence: zhjhuang2010@163.com; Tel.: +86-871-65032180
}

Received: 9 July 2019; Accepted: 29 July 2019; Published: 31 July 2019

\begin{abstract}
A novel functional ion-exchange/adsorption metal organic resin (MOR), TEBAC-HKUST-1, was prepared and characterized. Ethanedithiol was used as the grafting agent to introduce thiol groups onto HKUST-1, and 4-vinylbenzyl chloride was then grafted onto SH-HKUST-1 using thiol groups. Finally, the quaternary ammonium functional group was immobilized onto the carrier by performing a quaternization reaction. The structure and property of TEBAC-HKUST-1 MOR were characterized by TGA, $\mathrm{N}_{2}$ adsorption-desorption, FTIR, SEM, and XRD. TEBAC-HKUST-1 MOR was used to remove metal cyanide complexes from wastewater. The adsorption was rapid, and the metal cyanide complexes including $\mathrm{Pt}(\mathrm{CN})_{4}{ }^{2-}, \mathrm{Co}(\mathrm{CN})_{6}{ }^{3-}, \mathrm{Cu}(\mathrm{CN})_{3}{ }^{2-}$, and $\mathrm{Fe}(\mathrm{CN})_{6}{ }^{3-}$ were removed in $30 \mathrm{~min}$. TEBAC-HKUST-1 MOR exhibited a high stability in neutral and weak basic aqueous solutions. Furthermore, $\mathrm{Pt}(\mathrm{II})$ could be efficiently recovered through two-step elution. The recovery rate of $\mathrm{Pt}(\mathrm{II})$ for five cycles were over $92.0 \%$ in the mixture solution containing $\mathrm{Pt}(\mathrm{CN})_{4}{ }^{2-}, \mathrm{Co}(\mathrm{CN})_{6}{ }^{3-}$, $\mathrm{Cu}(\mathrm{CN})_{3}{ }^{2-}$, and $\mathrm{Fe}(\mathrm{CN})_{6}{ }^{3-}$. The kinetic data were best fitted with the pseudo second-order model. Moreover, the isothermal data were best fitted with the Langmuir model. The thermodynamic results show that the adsorption is a spontaneous and exothermic process. TEBAC-HKUST-1 MOR not only exhibited excellent ability for the rapid removal of metal cyanide complexes, but also provided a new idea for the extraction of noble metals from cyanide-contaminated water.
\end{abstract}

Keywords: metal organic resin; platinum cyanide; recovery

\section{Introduction}

Cyanide is one of the most dangerous contaminants in environment, threatening human health and ecological systems [1]. The World Health Organization (WHO) recommends that the level of cyanide in drinking water should be less than $0.05 \mathrm{mg} \mathrm{L}^{-1}[2,3]$. Pressure cyanidation has been extensively used in extracting noble metals from flotation concentrate in China [4]. A large number of platinum group metals containing $\mathrm{Pt}, \mathrm{Pd}, \mathrm{Rh}$, and $\mathrm{Ir}$ in cyanide effluents should be recycled. Therefore, removal of cyanide and recovery of noble metals from cyanide-contaminated water are important tasks. The main species of cyanide are free cyanide and metal cyanide complexes. In the past decades, various methods have been applied to remove metal cyanide complexes from wastewater, including biological degradation [5-7], chemical oxidation [8], and ion-exchange/adsorption [9]. Most metal cyanide complexes exhibit a wide range of biological stability compared to free cyanide ions; hence, metal cyanide complexes cannot be treated by biological degradation [6]. Chemical oxidation often results in undesired byproducts, which can cause secondary pollution to water body. Ion-exchange/adsorption is considered as a relatively low cost and highly efficient method for the treatment of ionic pollutants [10]. However, common ion-exchange organic resins exhibit a relatively slow sorption kinetics, low thermal and chemical stability, moderate selectivity, and poor regeneration and reusability for metal cyanide complexes [11]. 
Recently, metal organic resins (MORs) with ion-exchange/adsorption properties have attracted much attention owing to their fast ion-exchange kinetics, unique crystalline porous structure, high ion-exchange/adsorption capacity, and high selectivity for toxic ions [12]. MORs are known as the next-generation ion-exchange/adsorption adsorbents [13]. MORs exhibit an excellent ability to remove various hazardous contaminants in water, including $\mathrm{Cr}(\mathrm{VI})$ [14], $\mathrm{SeO}_{4}{ }^{2-} / \mathrm{SeO}_{3}{ }^{2-}$ [15], $\mathrm{PO}_{4}{ }^{3-}$ [16], $\mathrm{F}^{-}$[17], $\mathrm{ClO}_{4}^{-}$[18], $\mathrm{NO}_{3}{ }^{-} / \mathrm{NO}_{2}{ }^{-}$[19], $\mathrm{As}(\mathrm{V}) / \mathrm{As}(\mathrm{III})$ [20], $\mathrm{Hg}^{2+}$ [21], $\mathrm{Pb}^{2+}$ [22] and $\mathrm{Cd}^{2+}$ [23].

Because of the tunability of cations and anions, quaternary amine salts have been widely used in the extraction and separation of metal cyanide [24-27]. However, quaternary ammonium extraction agents have several drawbacks such as easily emulsified and unsuitable viscosity. An effective solution to these problems is the immobilization of quaternary amine salts onto a solid material with hydrophilic-lipophilic matrix [28].

Herein, a novel functional ion-exchange/adsorption metal organic resin (TEBAC-HKUST-1 MOR) was prepared by post-synthetic modification strategy. First, $\mathrm{Cu}^{2+}$ ions of HKUST-1 were chelated with the $\mathrm{S}$ atom of ethanedithiol. Ethanedithiol was used as the grafting agent to introduce thiol groups onto HKUST-1. Second, the 4-vinylbenzyl chloride was immobilized onto SH-HKUST-1 by the reaction of vinyl and thiol. Finally, quaternary ammonium functional groups were grafted onto the MOF matrix through quaternization reaction. To the best of our knowledge, the use of functional HKUST-1 as ion-exchange/adsorption MOR in the removal of metal cyanide complexes from wastewater has not been reported. The structure and property of TEBAC-HKUST-1 MOR were systematically characterized by thermogravimetric analysis (TGA), $\mathrm{N}_{2}$ adsorption-desorption, Fourier transform infrared (FTIR) spectroscopy, scanning electron microscopy (SEM), and X-ray diffraction (XRD).

Because of the combination of merits of quaternary ammonium ion exchange with high porosity of HKUST-1 [29], TEBAC-HKUST-1 MOR exhibited rapid ion-exchange/adsorption performance for $\mathrm{Pt}(\mathrm{CN})_{4}{ }^{2-}, \mathrm{Co}(\mathrm{CN})_{6}{ }^{3-}, \mathrm{Cu}(\mathrm{CN})_{3}{ }^{2-}$, and $\mathrm{Fe}(\mathrm{CN})_{6}{ }^{3-}$, and almost all the metal cyanide complexes could be removed in $30 \mathrm{~min}$. Furthermore, the adsorbed $\mathrm{Pt}(\mathrm{CN})_{4}{ }^{2-}$ could be selectively recovered by two-step elution. First, the loaded $\mathrm{Co}(\mathrm{CN})_{6}{ }^{3-}, \mathrm{Cu}(\mathrm{CN})_{3}{ }^{2-}$, and $\mathrm{Fe}(\mathrm{CN})_{6}{ }^{3-}$ on TEBAC-HKUST-1 MOR could be eluted using a $\mathrm{NaCl}$ solution. Subsequently, a $\mathrm{NH}_{4} \mathrm{SCN}$ solution was used to elute the loaded $\operatorname{Pt}(\mathrm{CN})_{4}{ }^{2-}$. TEBAC-HKUST-1 MOR exhibited efficient separation for $\mathrm{Pt}(\mathrm{CN})_{4}{ }^{2-}$ from a mixed metal cyanide complex mixture containing $\mathrm{Pt}(\mathrm{CN})_{4}{ }^{2-}, \mathrm{Co}(\mathrm{CN})_{6}{ }^{3-}, \mathrm{Fe}(\mathrm{CN})_{6}{ }^{3-}$, and $\mathrm{Cu}(\mathrm{CN})_{3}{ }^{2-}$, as well as excellent reusability. Adsorption isotherms, kinetics models, and adsorption thermodynamics of $\mathrm{Pt}(\mathrm{CN})_{4}{ }^{2-}$ were also systematically investigated.

\section{Results}

\subsection{Characterization}

\subsubsection{FTIR Spectra}

Figure 1 shows the FTIR spectra of HKUST-1, TEBAC-HKUST-1, and TEBAC-HKUST-1-Pt(CN) ${ }_{4}{ }^{2-}$. The bands at 1620 and $1438 \mathrm{~cm}^{-1}$ show the vibrations of carboxylate groups of HKUST- 1 while the strong band at 1566 and $1378 \mathrm{~cm}^{-1}$ assigned to bending stretching of benzene ring of the HKUST-1 [30]. The bands located at $770 \mathrm{~cm}^{-1}$ can be attributed to $\mathrm{Cu}-\mathrm{O}$ bond (Figure 1a) [31]. These characteristic peaks are consistent with the previously reported FTIR spectrum of HKUST-1. The characteristic vibrational band of C-S group appeared at $686 \mathrm{~cm}^{-1}$, indicating that thiol groups were successfully introduced into HKUST-1 matrix [32]. Furthermore, compared with those observed for the bare HKUST-1, some new peaks were observed at 2973, 2916, and $2849 \mathrm{~cm}^{-1}$, corresponding to the C-H stretching of alkyl groups [33], indicating that quaternary ammonium was successfully grafted onto SH-HKUST-1 framework through quaternization reaction (Figure 1b). Compared to TEBAC-HKUST-1, the IR spectra of adsorbed species of TEBAC-HKUST-1-Pt $(\mathrm{CN})_{4}{ }^{2-}$ did not exhibit any remarkable shift (Figure 1c), while new absorption peaks corresponding to the $\mathrm{C} \equiv \mathrm{N}$ stretching vibration of platinum cyanide were observed at $2208 \mathrm{~cm}^{-1}$ and $2182 \mathrm{~cm}^{-1}$ [34]. 


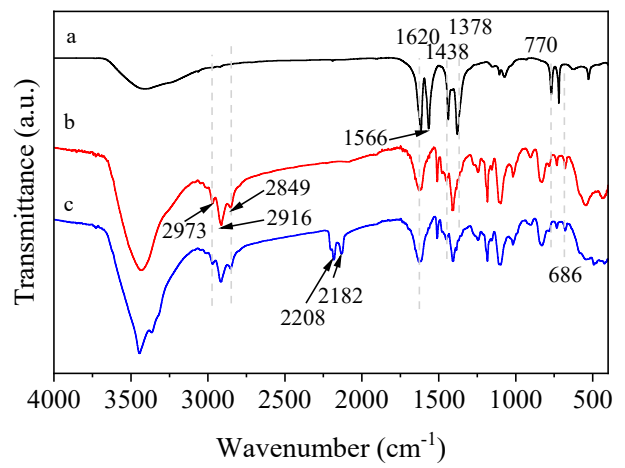

Figure 1. Fourier transform infrared (FTIR) spectra of the HKUST-1 (a), TEBAC-HKUST-1 (b), and TEBAC-HKUST-1-Pt(CN $)_{4}{ }^{2-}$ (c).

\subsubsection{XRD Spectra}

The XRD patterns of obtained samples HKUST-1, TEBAC-HKUST-1, after five adsorptiondesorption cycles TEBAC-HKUST-1 MOF at $\mathrm{pH}=8.0$, the simulated sample from the single crystal data of HKUST-1, and TEBAC-HKUST-1 MOR at different $\mathrm{pH}$ values are shown in Figure 2a, b, c, d and e, respectively. The main characteristic diffraction peaks of the as-synthesized HKUST-1 match well with those of simulated single-crystal structure (CCDC: 112954/www.ccdc.cam.ac.uk). Good crystallinity showed that the as-synthesized sample has a pure phase of HKUST-1. Compared with HKUST-1, the main characteristic diffraction peaks of TEBAC-HKUST-1 showed slight differences with those of HKUST-1, confirming that ligand functionalization does not change the original crystal structure of sample [32]. After five adsorption-desorption cycles at $\mathrm{pH}=8.0$, the intensities of diffraction peaks of TEBAC-HKUST-1 MOR slightly decreased, indicating that the crystallinity of MOR was only partial loss. The TEBAC-HKUST-1 MOR adsorbent exhibited a good stability and reusability.

To evaluate the chemical stability of target MOR, TEBAC-HKUST- 1 was first suspended in aqueous solutions at $\mathrm{pH}=7.0-12.0$, followed by XRD measurements to monitor the changes in the crystallinity of MOF. As shown in Figure 2e, the crystallinity of sample does not show a significant loss at various $\mathrm{pH}$ values ranging from 7.0 to 9.7 (room temperature). TEBAC-HKUST-1 showed a high-water stability in neutral and weakly basic aqueous solutions. When the $\mathrm{pH}$ of solution reached 11, TEBAC-HKUST-1 MOR partially decomposed.
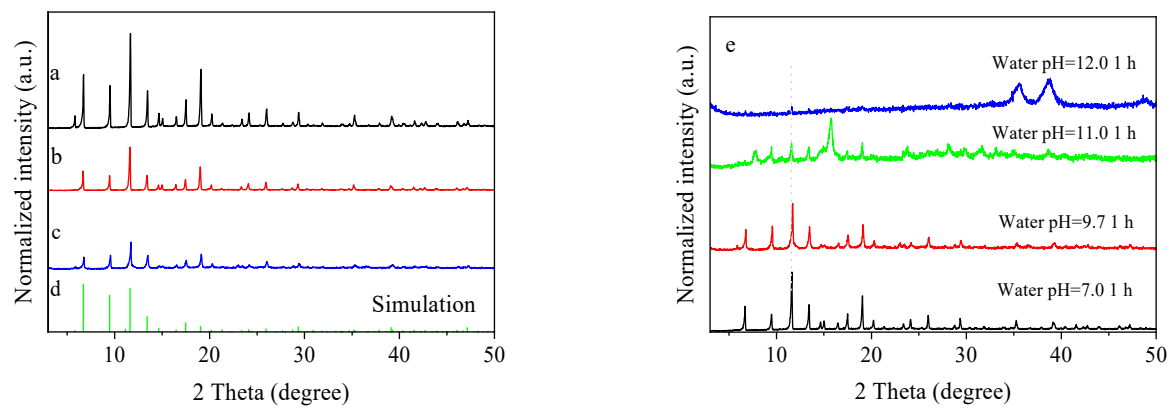

Figure 2. The X-ray diffraction (XRD) patterns of HKUST-1 (a), TEBAC-HKUST-1 (b), five cycles. $(\mathrm{pH}=8.0)(\mathbf{c})$, the simulated sample of HKUST-1 (d), and TEBAC-HKUST-1 metal organic resin (MOR) at different $\mathrm{pH}$ values (e).

\subsubsection{SEM Analysis}

Figure 3a-c shows the SEM images of as-prepared HKUST-1, TEBAC-HKUST-1 MOR, and recovered TEBAC-HKUST-1 MOR, respectively. HKUST-1 particles exhibited a regular octahedron shape with an average particle size of $20 \sim 30 \mu \mathrm{m}$. The morphology of as-synthesized HKUST-1 samples was consistent with that reported in literature [35]. Compared with that observed for bare HKUST-1, 
TEBAC-HKUST-1 MOR and the recovered TEBAC-HKUST-1 MOR maintained the same octahedron structure [36], indicating that HKUST-1 functionalization and adsorption reaction did not significantly affect the HKUST-1 structure, consistent with the XRD analyses.

a

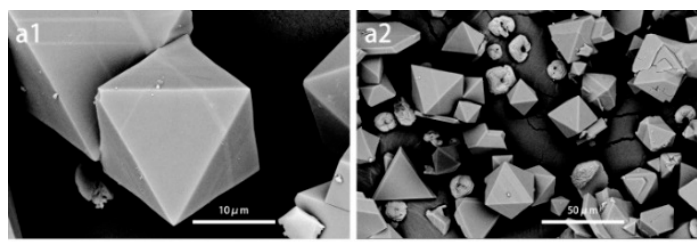

b
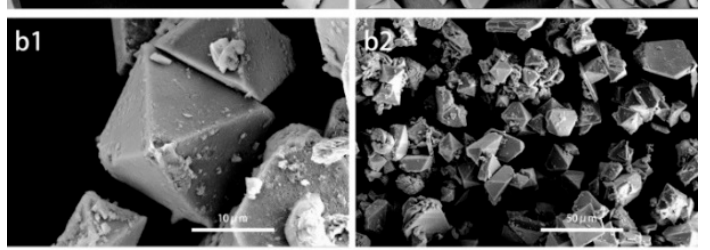

c

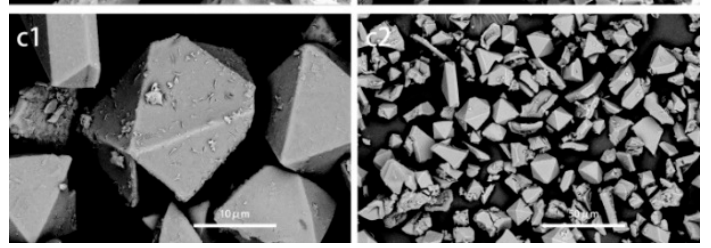

Figure 3. The scanning electron microscopy (SEM) images of HKUST-1 ( $\left.\mathbf{a}_{1}, \mathbf{a}_{2}\right)$, TEBAC-HKUST-1 $\left(\mathbf{b}_{1}, \mathbf{b}_{2}\right)$, and the recovered TEBAC-HKUST-1 $\left(\mathbf{c}_{1}, \mathbf{c}_{2}\right)$.

\subsubsection{TGA}

The TG curves of HKUST-1 and TEBAC-HKUST-1 MOR are shown in Figure 4. The TG curves of HKUST-1 show three weight loss signals at $40-150{ }^{\circ} \mathrm{C}, 150-300{ }^{\circ} \mathrm{C}$, and $300-360{ }^{\circ} \mathrm{C}$, corresponding to the loss of physically adsorbed water, the desorption of coordinated water with copper ion or crystal water of HKUST-1, and collapse of HKUST-1 framework, respectively [37]. For the TEBAC-HKUST-1 MOR, the weight loss can also be divided into three stages. First, the departure of adsorbed or coordinated water molecules inside the sample $\left(<200{ }^{\circ} \mathrm{C}\right)$. The percent of weight loss of HKUST-1 from $40{ }^{\circ} \mathrm{C}$ to $200{ }^{\circ} \mathrm{C}$ was more than TEBAC-HKUST-1 MOR, because a part of the sites for water in HKUST-1 framework was replaced with the grafted quaternary ammonium [38]. Second, the weight loss was due to the decomposition of immobilized quaternary ammonium $\left(200-285^{\circ} \mathrm{C}\right)$ [38]. The third weight loss stage above $285^{\circ} \mathrm{C}$ was assigned to the collapse of MOR frameworks. TGA confirmed that TEBAC-HKUST-1 MOR has good thermal stability.

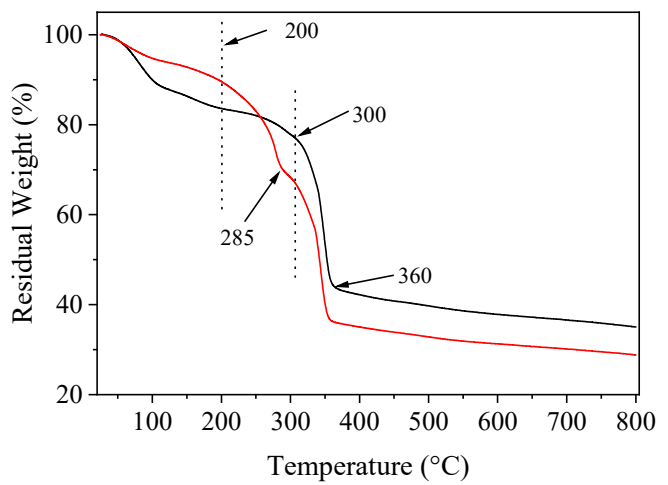

Figure 4. Thermogravimetric analysis of HKUST-1 (black) and TEBAC-HKUST-1 (red). 


\subsection{5. $\mathrm{N}_{2}$ Adsorption-Desorption Isotherms}

Figure 5 shows the $\mathrm{N}_{2}$ adsorption-desorption isotherms of as-prepared HKUST-1 and TEBAC-HKUST-1 MOR. The $\mathrm{N}_{2}$ adsorption-desorption isotherm of as-synthesized HKUST-1 samples exhibited type-I isotherms (Figure 5a). The as-prepared materials are therefore essentially microporous, consistent with the previously reported $\mathrm{N}_{2}$ adsorption-desorption isotherm for HKUST-1 [39]. Compared with bare HKUST-1, the $\mathrm{N}_{2}$ adsorption-desorption isotherms of TEBAC-HKUST-1 MOR showed similar type-IV isotherms (Figure 5b). This is probably because HKUST-1 framework was partially decomposed during functionalization, providing some mesopores in the MOR. Similar results were reported by Alavi and co-workers [40]. The surface area and total pore volume of as-prepared HKUST-1 and TEBAC-HKUST-1 MOR (N, $1.5 \mathrm{wt} \%)$ are shown in Table 1. Compared with as-prepared HKUST-1, both the BET surface area and total pore volume of TEBAC-HKUST-1 MOR decreased significantly. This is because the pores of as-prepared HKUST-1 framework were partially occupied by functionalized groups. This also indicates that quaternary ammonium was successfully immobilized onto the MOF framework.
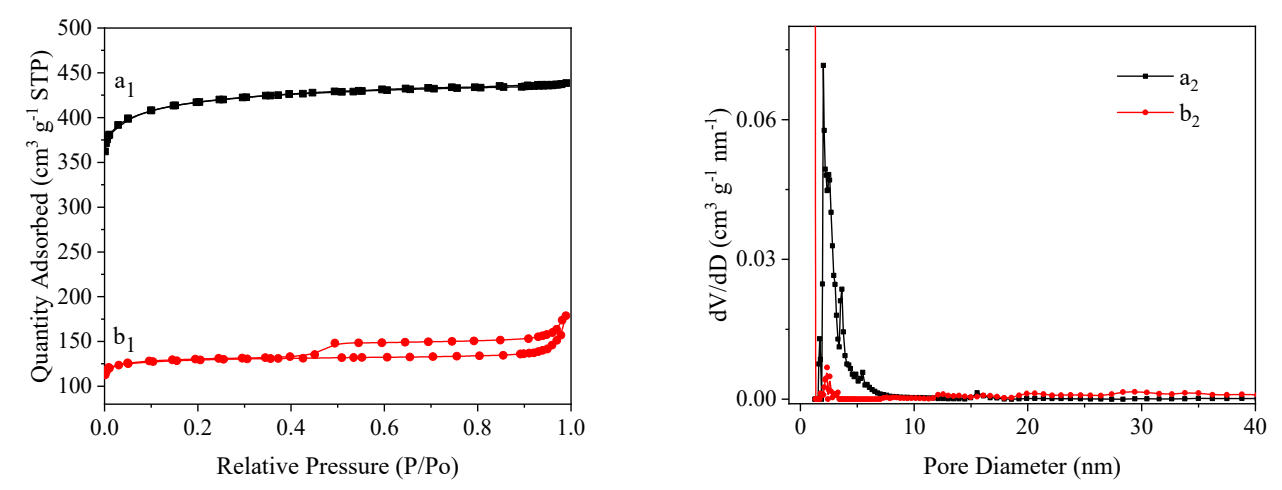

Figure 5. Nitrogen adsorption-desorption isotherm and corresponding NLDFT pore-size distribution

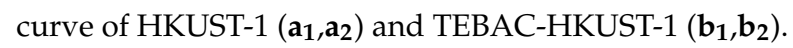

Table 1. The surface area and total pore volume of samples.

\begin{tabular}{ccc}
\hline Sample & BET Specific Surface Area $\mathbf{~ m}^{\mathbf{2}} \mathbf{g}^{\mathbf{- 1}}$ & Pore Volume $\mathbf{~ c m}^{\mathbf{3}} \mathbf{g}^{\mathbf{- 1}}$ \\
\hline as-prepared HKUST-1 & 1651.896 & 0.738 \\
TEBAC-HKUST-1 & 523.703 & 0.260 \\
\hline
\end{tabular}

\subsubsection{XPS}

As shown in Figure 6a, C, O, and Cu were mainly observed for HKUST-1 and TEBAC-HKUST-1 because of their skeleton structure according to the wide-scan XPS spectrum. Figure 6a also shows that the XPS spectrum of TEBAC-HKUST-1 MOR contains six elements: $\mathrm{Cu}, \mathrm{O}, \mathrm{C}, \mathrm{N}, \mathrm{Cl}$, and S.

Figure $6 \mathrm{~b}$ shows the sulfur $2 \mathrm{p}$ XPS spectrum of TEBAC-HKUST-1 MOR sample. The $\mathrm{S} 2 \mathrm{p}$ peak was resolved into three components; the binding energy (BE) components were observed at 164.8, 163.4, and $162.0 \mathrm{eV}$, corresponding to $\mathrm{H}-\mathrm{S}, \mathrm{C}-\mathrm{S}$, and $\mathrm{Cu}-\mathrm{S}$ bonds, respectively [41,42]. Figure 6c shows that only one peak appeared at $401.9 \mathrm{eV}$ in the $\mathrm{N}$ 1s XPS high-resolution spectra of TEBAC-HKUST-1 MOR, consistent with those for previously reported quaternary ammonium [43]. This indicates that quaternization reaction occurred, and quaternary ammonium functional groups were grafted onto the MOFs.

By comparing the wide-scan spectra before and after the adsorption of $\mathrm{Pt}(\mathrm{CN})_{4}{ }^{2-}, \mathrm{Pt} 4 \mathrm{f}$ bands were clearly observed in the spectra after the adsorption of $\mathrm{Pt}(\mathrm{II})$, indicating that $\mathrm{Pt}(\mathrm{CN})_{4}{ }^{2-}$ ions were successfully adsorbed on TEBAC-HKUST-1 MOR. After the adsorption, a new peak was observed in the $\mathrm{N}$ 1s spectra of TEBAC-HKUST-1-Pt(CN $)_{4}{ }^{2-}$ at a $\mathrm{BE}$ of $398.6 \mathrm{eV}$, indicating that $\mathrm{CN}^{-}$is adsorbed on TEBAC-HKUST-1 MOR (Figure 6d) [44]. Furthermore, from the Pt 4f spectra (Figure 6e), Pt was clearly 
observed, confirming the successful adsorption of $\mathrm{Pt}(\mathrm{CN})_{4}{ }^{2-}$ on the modified MOFs. The $\mathrm{Pt} 4 \mathrm{f}_{7 / 2}$ peak at a $\mathrm{BE}$ of $73.20 \mathrm{eV}(\mathrm{DS}=3.35 \mathrm{eV})$ corresponded to platinum cyanide groups $\left(\mathrm{Pt}(\mathrm{CN})_{4}{ }^{2-}\right)$. By comparing the XPS spectra of pristine $\mathrm{Pt}(\mathrm{CN})_{4}{ }^{2-}$ with that after the adsorption (Figure 6e), the adsorption of $\mathrm{Pt}(\mathrm{CN})_{4}{ }^{2-}$ on TEBAC-HKUST-1 MOR was confirmed to exert no effect on $\mathrm{Pt} 4 \mathrm{f}$ spectra, indicating that a coordinate covalent bond was not formed between $\mathrm{Pt}(\mathrm{CN})_{4}{ }^{2-}$ and TEBAC-HKUST-1 MOR. Therefore, the XPS measurements further supported that ion-exchange mechanisms are possibly the major adsorption mechanisms. The results are in consistent with those obtained from the FTIR spectra.
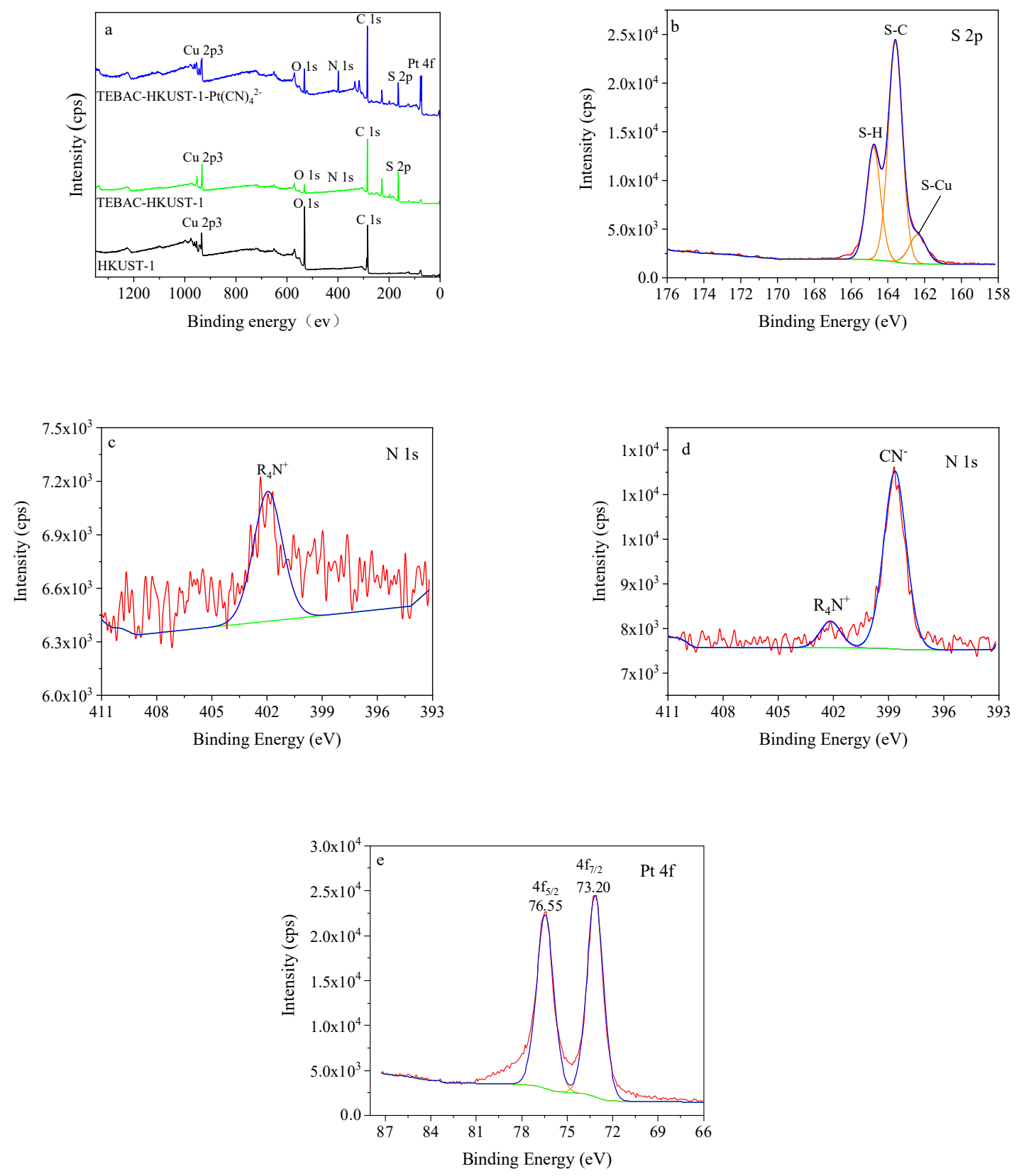

Figure 6. The wide XPS spectra (a); S 2p XPS spectrum of TEBAC-HKUST-1 (b); nitrogen 1s XPS spectrum of TEBAC-HKUST-1 (c); nitrogen 1s XPS spectrum of TEBAC-HKUST-1-Pt(CN) ${ }_{4}{ }^{2-}(\mathrm{d})$; $\mathrm{Pt} 4 \mathrm{f}$ XPS spectrum of TEBAC-HKUST-1-Pt(II) (e).

\subsection{Effects of $p H$}

The effects of $\mathrm{pH}$ on the adsorption of metal cyanide complexes were evaluated using single-component solutions at $25^{\circ} \mathrm{C}$. The experimental parameters were fixed as follows: $10 \mathrm{mg}$ of 
TEBAC-HKUST-1 MOR, adsorption time of $30 \mathrm{~min}$, initial Pt(II), $\mathrm{Fe}(\mathrm{III}), \mathrm{Cu}(\mathrm{I})$, or $\mathrm{Co}(\mathrm{III})$ concentration, $50.0 \mathrm{mgL}^{-1}$; solution volume, $20 \mathrm{~mL}$. The batch system was used for evaluating the effects of $\mathrm{pH}$ on adsorption. Equilibrium loadings of $\mathrm{Pt}(\mathrm{II}), \mathrm{Fe}(\mathrm{III}), \mathrm{Cu}(\mathrm{I})$, or $\mathrm{Co}(\mathrm{III})$ were examined at various $\mathrm{pH}$ values ranging from 7.0 to 10.0. The results show that with an increase in the $\mathrm{pH}$ from 7.0 to 8.5 , the equilibrium adsorption capacities ( $\left.\mathrm{q}_{\mathrm{e}}\right)$ of $\mathrm{Pt}(\mathrm{II}), \mathrm{Fe}(\mathrm{III}), \mathrm{Cu}(\mathrm{I})$, or $\mathrm{Co}(\mathrm{III})$ remained almost constant, and with further increase in solution $\mathrm{pH}$, the $\mathrm{q}_{\mathrm{e}}$ values significantly decreased. At a higher $\mathrm{pH}, \mathrm{OH}^{-}$ions are abundant in solution, thus making $\mathrm{OH}^{-}$ions compete with $\mathrm{Pt}(\mathrm{CN})_{4}{ }^{2-}, \mathrm{Co}(\mathrm{CN})_{6}{ }^{3-}, \mathrm{Cu}(\mathrm{CN})_{3}{ }^{2-}$, and $\mathrm{Fe}(\mathrm{CN})_{6}{ }^{3-}$, causing a decrease in the qe values of metal cyanide complexes [45]. The experimental results indicate that the main mechanism for the adsorption of metal cyanide complexes from aqueous solutions followed an ion-exchange reaction:

$$
\mathrm{nM}-\mathrm{R}_{3} \mathrm{~N}^{+} \mathrm{Cl}^{-}(\mathrm{S})+\mathrm{Me}(\mathrm{CN}){ }_{\mathrm{m}}{ }^{\mathrm{n}-}(\mathrm{aq})=\left(\mathrm{M}-\mathrm{R}_{3} \mathrm{~N}\right)_{\mathrm{n}}{ }^{+} \mathrm{Me}(\mathrm{CN})_{\mathrm{m}}{ }^{\mathrm{n}-}(\mathrm{s})+\mathrm{nCl}^{-}(\mathrm{aq})
$$

Here, M denotes the MOR matrix. Finally, pH 8 was selected for the subsequent experiments.

\subsection{Maximum Adsorption Capacities}

The batch system was used for the removal of metal cyanide complexes from aqueous solutions. The experimental maximum sorbent capacity was obtained according to previously reported method. The obtained maximum sorbent capacity of TEBAC-HKUST-1 MOR (N, $1.5 \mathrm{wt} \%)$ was also compared with AC and as-prepared HKUST-1. The experimental data are shown in Figure 7. As shown in Figure 7, TEBAC-HKUST-1 MOR exhibited excellent adsorption performance towards $\mathrm{Pt}(\mathrm{CN})_{4}{ }^{2-}$, $\mathrm{Co}(\mathrm{CN})_{6}{ }^{3-}, \mathrm{Cu}(\mathrm{CN})_{3}{ }^{2-}$, and $\mathrm{Fe}(\mathrm{CN})_{6}{ }^{3-}$ compared with AC and as-prepared HKUST-1, indicating that the quaternary ammonium group plays a key role in the removal of metal cyanide complexes.

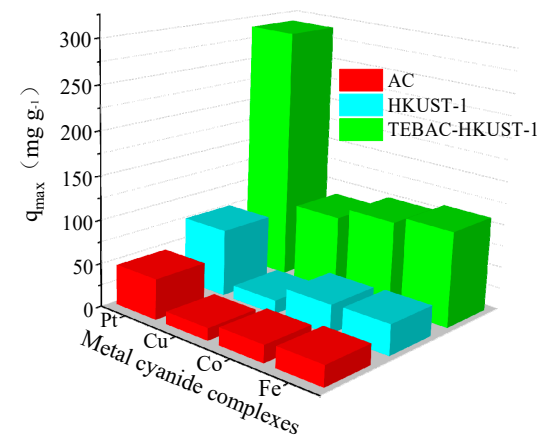

Figure 7. Maximal adsorption capacity for the metal cyanide complexes.

\subsection{Adsorption Kinetics}

To evaluate the kinetic parameters of $\mathrm{Pt}(\mathrm{CN})_{4}{ }^{2-}$ on TEBAC-HKUST-1 MOR(N, $\left.1.5 \mathrm{wt} \%\right)$, pseudo-first order, pseudo-second order, and intraparticle models were used to fit the experimental data. The three models can be expressed as Equations (2-4), respectively:

$$
\begin{gathered}
\lg \left(\mathrm{q}_{\mathrm{e}}-\mathrm{q}_{\mathrm{t}}\right)=\lg \mathrm{q}_{\mathrm{e}}-\mathrm{k}_{1} \mathrm{t} / 2.303, \\
\mathrm{t} / \mathrm{q}_{\mathrm{t}}=1 /\left(\mathrm{k}_{2} \mathrm{q}^{2}\right)+\mathrm{t} / \mathrm{q}_{\mathrm{e}}, \\
\mathrm{q}_{\mathrm{t}}=\mathrm{k}_{\mathrm{p}} \mathrm{t}^{1 / 2}+\mathrm{C},
\end{gathered}
$$

Here, $\mathrm{q}_{\mathrm{e}}$ and $\mathrm{q}_{\mathrm{t}}$ are the amount of loading of $\mathrm{Pt}(\mathrm{II})$ at equilibrium and any time $\left(\mathrm{mg} \mathrm{g}^{-1}\right)$, respectively; $\mathrm{k}_{1}$ is the rate constant of pseudo-first-order kinetics $\left(\mathrm{min}^{-1}\right) ; \mathrm{k}_{2}$ is the pseudo-second-order constant $\left(\mathrm{g} \mathrm{mg}^{-1} \mathrm{~min}^{-1}\right) ; \mathrm{k}_{\mathrm{p}}$ is the intraparticle diffusion rate constant $\left(\mathrm{mg} \mathrm{g}^{-1} \mathrm{~min}^{-0.5}\right) ; \mathrm{C}$ is the boundary layer thickness. The experimental conditions were as follows: $10 \mathrm{mg}$ of MOR; equilibrium 
time ( $\mathrm{t}<30 \mathrm{~min}$ ); initial $\mathrm{Pt}(\mathrm{II})$ concentration, $100 \mathrm{mg} \mathrm{L}^{-1} ; \mathrm{pH}=8.0$, solution volume, $20 \mathrm{~mL}$. The parameters for the three kinetic models are shown in Table 2.

Table 2. Kinetic parameters of $\mathrm{Pt}(\mathrm{II})$ adsorption onto the TEBAC-HKUST-1 MOR.

\begin{tabular}{cccccc}
\hline \multicolumn{2}{c}{ Pseudo-First-Order Model } & \multicolumn{2}{c}{ Pseudo-Second-Order Model } & \multicolumn{2}{c}{ Intra-Particle Diffusion Model } \\
\hline $\mathrm{q}_{\mathrm{e} \text {,exp. }}\left(\mathrm{mg} \mathrm{g}^{-1}\right)$ & 235.5 & $\mathrm{q}_{\mathrm{e} \text {,exp. }}\left(\mathrm{mg} \mathrm{g}^{-1}\right)$ & 235.5 & $\mathrm{~K}_{\mathrm{p}}\left(\mathrm{mg} \mathrm{g}^{-1} \mathrm{~min}^{-0.5}\right)$ & 5.533 \\
$\mathrm{q}_{\mathrm{e} \text {, cal. }}\left(\mathrm{mg} \mathrm{g}^{-1}\right)$ & 61.19 & $\mathrm{q}_{\mathrm{e}, \mathrm{cal}}\left(\mathrm{mg} \mathrm{g}^{-1}\right)$ & 238.1 & $\mathrm{C}$ & 208.2 \\
$\mathrm{k}_{1}\left(\mathrm{~min}^{-1}\right)$ & 0.1820 & $\mathrm{k}_{2}\left(\mathrm{~g} \mathrm{mg}^{-1} \mathrm{~min}^{-1}\right)$ & 0.0123 & $\mathrm{R}^{2}$ & 0.8530 \\
$\mathrm{R}^{2}$ & 0.8470 & $\mathrm{R}^{2}$ & 0.9994 & & $\mathrm{R}^{2}$ \\
\hline
\end{tabular}

As shown in Table 2, the adsorption kinetics for Pt(II) well fitted with the pseudo-second-order kinetic model. Compared with polymer resin, the adsorption of $\mathrm{Pt}(\mathrm{CN})_{4}{ }^{2-}$ using TEBAC-HKUST-1 MOR was more rapid; the equilibrium was established within $30 \mathrm{~min}$ (Figure 8).
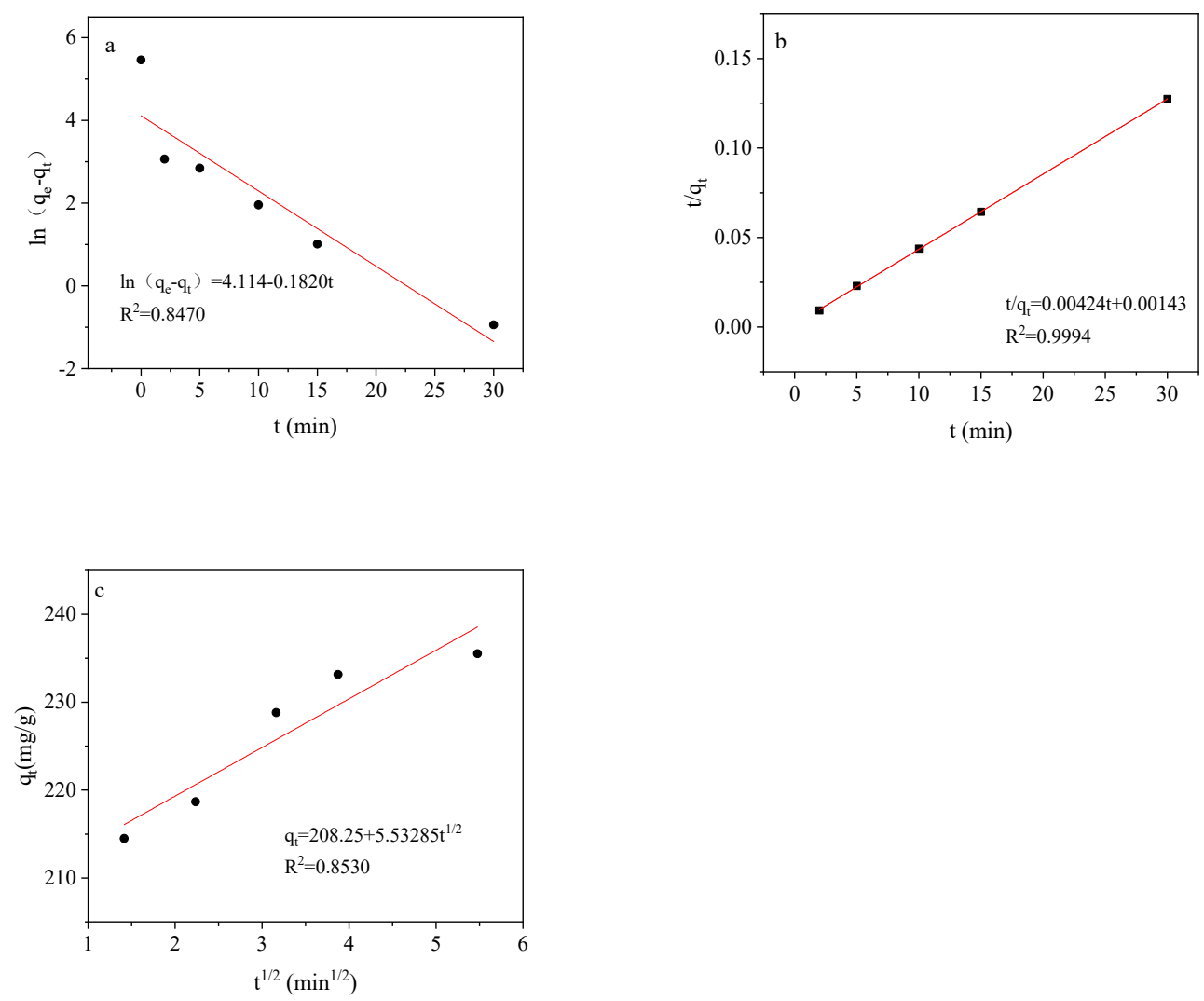

Figure 8. Pseudo-first-order (a), pseudo-second-order (b), and intra-particle diffusion model (c) at $298 \mathrm{~K}$.

Because of unique tunnels and crystalline porous structure of TEBAC-HKUST-1 MOR, $\mathrm{Pt}(\mathrm{CN})_{4}{ }^{2-}$ could rapidly spread into the MOR matrix. In contrast, a hydrophobic polymer resin and AC, TEBAC-HKUST-1 showed a quick adsorption equilibrium for $\mathrm{Pt}(\mathrm{CN})_{4}{ }^{2-}$. More than $2 \mathrm{~h}$ was taken when $\mathrm{Pt}(\mathrm{CN})_{4}{ }^{2-}$ was adsorbed on the polymer resin or $\mathrm{AC}$.

\subsection{Sorption Isotherms}

Isotherm models show how metal cyanide complexes are distributed between the solution and TEBAC-HKUST-1(N, $1.5 \mathrm{wt} \%$ ). In this study, Langmuir and Freundlich isotherm models were used for fitting the experimental data. The experimental parameters were as follows: $10 \mathrm{mg}$ of MOR; $\mathrm{t}=30 \mathrm{~min}$; 
$\mathrm{pH}=8.0$; initial $\mathrm{Pt}(\mathrm{II})$ concentration, $10-200 \mathrm{mg} \mathrm{L}^{-1}$; solution volume, $20 \mathrm{~mL}$. The Langmuir and Freundlich equilibrium models are as follows:

$$
\begin{gathered}
\mathrm{C}_{\mathrm{e}} / \mathrm{q}_{\mathrm{e}}=1 /\left(\mathrm{q}_{\mathrm{m}} \mathrm{b}\right)+\mathrm{C}_{\mathrm{e}} / \mathrm{q}_{\mathrm{m}}, \\
\lg \mathrm{q}_{\mathrm{e}}=\lg \mathrm{K}_{\mathrm{F}}+\mathrm{n}^{-1} \lg \mathrm{C}_{\mathrm{e}},
\end{gathered}
$$

Here, $\mathrm{q}_{\mathrm{m}}, \mathrm{b}, \mathrm{K}_{\mathrm{F}}$ and $1 / \mathrm{n}$ are the maximum adsorption capacity $\left(\mathrm{mg} \mathrm{g}^{-1}\right)$, Langmuir adsorption equilibrium constant $\left(\mathrm{L} \mathrm{mg}^{-1}\right)$, Freundlich constant $\left(\mathrm{L} \mathrm{g}^{-1}\right)$, and adsorption intensity, respectively. The parameters for the two isotherm models are shown in Table 3 and Figure 9.

\begin{tabular}{|c|c|c|c|c|c|c|c|}
\hline \multirow{2}{*}{ Metal } & \multirow{2}{*}{$\mathrm{q}_{\mathrm{m}}^{\mathrm{a}}(\mathrm{mg} \mathrm{g}-1)$} & \multicolumn{3}{|c|}{ Langmuir isotherm } & \multicolumn{3}{|c|}{ Freundlich isotherm } \\
\hline & & $\mathrm{qm}^{\mathrm{b}}\left(\mathrm{mg} \mathrm{g}^{-1}\right)$ & $b\left(\mathrm{~L} \mathrm{mg}^{-1}\right)$ & $\mathbf{R}^{2}$ & $K_{f}\left(L^{-1}\right)$ & n & $\mathbf{R}^{2}$ \\
\hline $\mathrm{Pt}$ & 290.2 & 289.9 & 10.17 & 0.9998 & 206.25 & 10.64 & 0.9535 \\
\hline
\end{tabular}

Table 3. Langmuir and Freundlich isotherm parameters of TEBAC-HKUST-1.
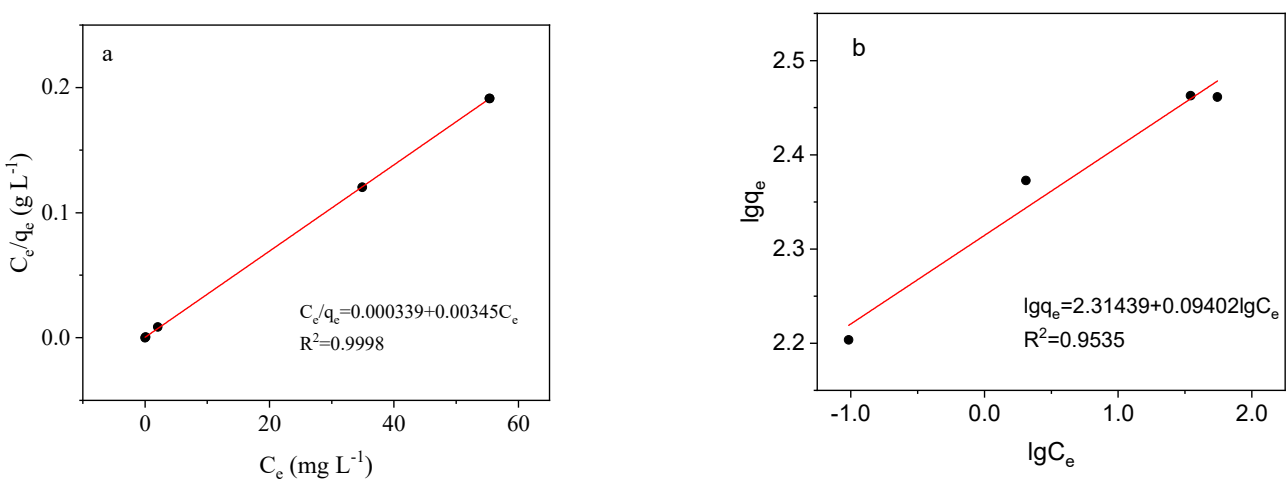

Figure 9. Langmuir (a), and Freundlich isotherm models (b).

As shown in Table 3 and Figure 9, the adsorption of $\mathrm{Pt}(\mathrm{CN})_{4}{ }^{2-}$ on TEBAC-HKUST-1 MOR well conforms to the Langmuir equation. The $\mathrm{q}_{\mathrm{m}}$ value was calculated from the Langmuir equation to be $289.9 \mathrm{mg} \mathrm{g}^{-1}$, slightly lower than the maximum experimental adsorption capacity of $290.2 \mathrm{mg} \mathrm{g}^{-1}$. Moreover, TEBAC-HKUST-1 MOR exhibited a higher maximum adsorption capacity than other sorbents reported earlier (Table 4).

Table 4. Comparison of the maximum adsorption capacity and adsorption time for $\mathrm{Pt}(\mathrm{CN})_{4}{ }^{2-}$ with polymer resins and activated carbon.

\begin{tabular}{ccccc}
\hline Adsorbent & Capacity $\left(\mathbf{m g ~ g}^{-\mathbf{1}}\right)$ & Adsorption Time (h) & Optimum $\mathbf{p H}$ & Ref. \\
\hline Polymer resins & $10-80$ & $6-48 \mathrm{~h}$ & 10.0 & {$[11,46]$} \\
Activated carbon & $4-25 \mathrm{mg} \mathrm{g}^{-1}$ & $3-12 \mathrm{~h}$ & 10.5 & {$[47,48]$} \\
TEBAC-HKUST-1 & $290.2 \mathrm{mg} \mathrm{g}^{-1}$ & 0.5 & 8 & Present work \\
\hline
\end{tabular}

\subsection{Thermodynamic Parameters}

The thermodynamic parameters including $\Delta \mathrm{H}, \Delta \mathrm{G}$, and $\Delta \mathrm{S}$ were measured according to the following Equation:

$$
\begin{gathered}
\Delta \mathrm{G}=\Delta \mathrm{H}-\mathrm{T} \Delta \mathrm{S}, \\
\mathrm{K}_{\mathrm{C}}=\left(\mathrm{C}_{0}-\mathrm{C}_{\mathrm{e}}\right) \mathrm{V} /\left(\mathrm{MC}_{\mathrm{e}}\right), \\
\ln \mathrm{K}_{\mathrm{C}}=\Delta \mathrm{H} /(\mathrm{R} \mathrm{T})+\Delta \mathrm{S} / \mathrm{R},
\end{gathered}
$$


where $\mathrm{Kc}, \mathrm{C}_{\mathrm{o}}, \mathrm{C}_{\mathrm{e}}, \mathrm{V}$, and $\mathrm{M}$ are the equilibrium constant, initial concentration, equilibrium concentration, volume of $\mathrm{Pt}(\mathrm{CN})_{4}{ }^{2-}$ solution, and mass of TEBAC-HKUST-1 MOR, respectively. The values of $\Delta \mathrm{H}$ and $\Delta \mathrm{S}$ can be obtained from the linearized plot of $\operatorname{lnKc}$ versus $\mathrm{T}^{-1}$ (Figure 10). The thermodynamic parameters for the absorption of $\mathrm{Pt}(\mathrm{CN})_{4}{ }^{2-}$ are shown in Table 5. A negative value of $\Delta \mathrm{H}$ suggests exothermic reaction. Negative $\Delta S$ indicates a decreased randomness at the two-phase interface during the adsorption of $\mathrm{Pt}(\mathrm{CN})_{4}{ }^{2-}$ on TEBAC-HKUST-1 MOR [49,50]. A negative value of $\Delta \mathrm{G}$ confirmed that the reaction was spontaneous. The values of $\Delta \mathrm{G}$ increases with increasing temperature, indicating that the adsorption is more spontaneous at lower temperatures.

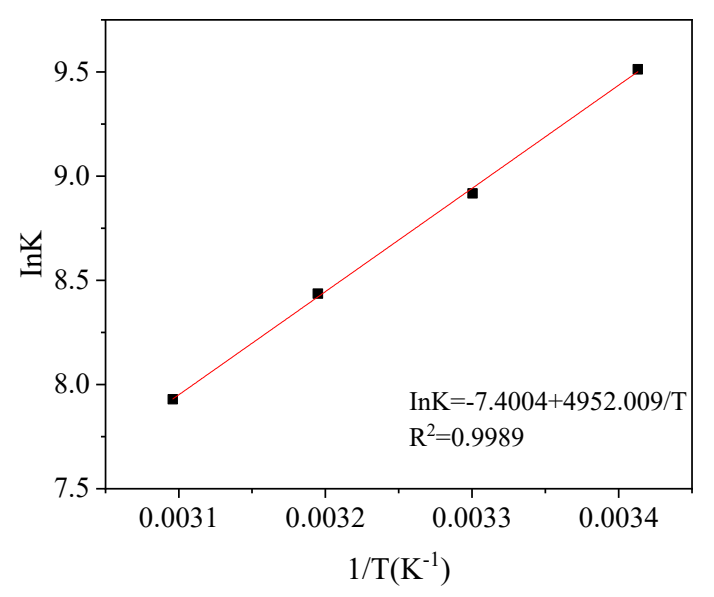

Figure 10. Van't Hoff plot for the investigated adsorbents.

Table 5. Thermodynamic parameters for the absorption of $\mathrm{Pt}(\mathrm{CN})_{4}{ }^{2-}$.

\begin{tabular}{|c|c|c|c|}
\hline Temperature (K) & $\Delta \mathrm{G}\left(\mathrm{kJ} \mathrm{mol}^{-1}\right)$ & $\Delta \mathrm{S}\left(\mathrm{J} \mathrm{mol}^{-1} \mathrm{~K}^{-1}\right)$ & $\Delta \mathrm{H}\left(\mathrm{kJ} \mathrm{mol}^{-1}\right)$ \\
\hline 293.15 & -23.13 & \multirow{4}{*}{-61526.9} & \multirow{4}{*}{-41.17} \\
\hline 303.15 & -22.51 & & \\
\hline 313.15 & -21.90 & & \\
\hline 323.15 & -21.29 & & \\
\hline
\end{tabular}

\subsection{Removal of Metal Cyanide Complexes and Recovery of Pt(II)}

TEBAC-HKUST-1 MOR was used for the removal of metal cyanide complexes and recovery of $\mathrm{Pt}(\mathrm{CN})_{4}{ }^{2-}$ from a mixture. Typically, $100 \mathrm{mg}$ of TEBAC-HKUST-1 MOR(N, $\left.1.5 \mathrm{wt} \%\right)$ was added to a $100 \mathrm{~mL}$ mixture containing $\mathrm{Pt}(\mathrm{CN})_{4}{ }^{2-}, \mathrm{Co}(\mathrm{CN})_{6}{ }^{3-}, \mathrm{Fe}(\mathrm{CN})_{6}{ }^{3-}$, and $\mathrm{Cu}(\mathrm{CN})_{3}{ }^{2-}$. Batch adsorption experiments were carried out under optimum conditions. The adsorption rate of all four metal cyanide complexes was over $99.0 \%$ in the mixture.

Furthermore, the adsorbed $\mathrm{Co}(\mathrm{CN})_{6}{ }^{3-}, \mathrm{Cu}(\mathrm{CN})_{3}{ }^{2-}$, and $\mathrm{Fe}(\mathrm{CN})_{6}{ }^{3-}$ could be selectively eluted by $1.5 \mathrm{~mol} \mathrm{~L}^{-1} \mathrm{NaCl}$ solution, whereas the elution percentage of $\mathrm{Pt}(\mathrm{CN})_{4}{ }^{2-}$ was less than $1.0 \%$ [51]. Finally, loaded $\mathrm{Pt}(\mathrm{CN})_{4}{ }^{2-}$ could be eluted using a $2.0 \mathrm{~mol} \mathrm{~L}^{-1} \mathrm{NH}_{4} \mathrm{SCN}$ solution. The recovery rate of $\mathrm{Pt}(\mathrm{CN})_{4}{ }^{2-}$ was over $97.0 \%$. The adsorbent can be regenerated by washing with a saturated sodium chloride solution. The experimental results show that TEBAC-HKUST-1 MOR could not only be used to efficiently remove metal cyanide complexes, but also could be used to selectively recycle Pt from mixed metal cyanide complexes.

The charge density of $\mathrm{Pt}(\mathrm{CN})_{4}{ }^{2-}$ is less than those of $\mathrm{Cu}(\mathrm{CN})_{3}{ }^{2-}, \mathrm{Co}(\mathrm{CN})_{6}{ }^{3-}$, and $\mathrm{Fe}(\mathrm{CN})_{6}{ }^{3-}$. Fewer water molecules are required to stabilize $\mathrm{Pt}(\mathrm{CN})_{4}{ }^{2-}$ compared to $\mathrm{Co}(\mathrm{CN})_{6}{ }^{3-}, \mathrm{Fe}(\mathrm{CN})_{6}{ }^{3-}$, and $\mathrm{Cu}(\mathrm{CN})_{3}{ }^{2-}$ anions in the aqueous solution. Based on the principle of minimum charge density, $\mathrm{Pt}(\mathrm{CN})_{4}{ }^{2-}$ should exhibit a higher affinity with quaternary ammonium cations compared to $\mathrm{Cu}(\mathrm{CN})_{3}{ }^{2-}, \mathrm{Co}(\mathrm{CN})_{6}{ }^{3-}$, or $\mathrm{Fe}(\mathrm{CN})_{6}{ }^{3-}$. Therefore, $\mathrm{Cu}(\mathrm{CN})_{3}{ }^{2-}, \mathrm{Co}(\mathrm{CN})_{6}{ }^{3-}$, and $\mathrm{Fe}(\mathrm{CN})_{6}{ }^{3-}$ adsorbed on TEBAC-HKUST-1 MOR could be eluted more easily compared to $\mathrm{Pt}(\mathrm{CN})_{4}{ }^{2-}$. Hence, $\mathrm{Cu}(\mathrm{CN})_{3}{ }^{2-}, \mathrm{Co}(\mathrm{CN})_{6}{ }^{3-}$, and $\mathrm{Fe}(\mathrm{CN})_{6}{ }^{3-}$ can be preferentially exchanged with $\mathrm{Cl}^{-}$anions. Based on the "perchlorate effect," the size of $\mathrm{SCN}^{-}$ 
is greater than that of $\mathrm{Cl}^{-}$, leading to charge density of $\mathrm{SCN}^{-}$lower than that of $\mathrm{Cl}^{-}$. Therefore, the interaction of $\mathrm{SCN}^{-}$with $\mathrm{M}-\mathrm{R}_{3} \mathrm{~N}^{+}$is considerably stronger than that of $\mathrm{Cl}^{-}$, consistent with the experimental results. The adsorbed $\mathrm{Pt}(\mathrm{CN})_{4}{ }^{2-}$ on TEBAC-HKUST-1 MOR could be completely eluted with $\mathrm{SCN}^{-}$. The elution reaction for $\mathrm{SCN}^{-}$ion might involve ion exchange:

$$
\left.\left(\mathrm{M}-\mathrm{R}_{3} \mathrm{~N}\right)\right)_{2}{ }^{+} \mathrm{Pt}(\mathrm{CN})_{4}{ }^{2-}(\mathrm{s})+2 \mathrm{SCN}^{-}(\mathrm{aq})=2 \mathrm{M}-\mathrm{R}_{3} \mathrm{~N}^{+} \mathrm{SCN}^{-}(\mathrm{s})+\mathrm{Pt}(\mathrm{CN})_{4}{ }^{2-}(\mathrm{aq}),
$$

where M denotes TEBAC-HKUST-1 MOR matrix.

\subsection{Regeneration Experiment}

To investigate the regeneration ability of TEBAC-HKUST- $1(\mathrm{~N}, 1.5 \mathrm{wt} \%)$, the recovery rates of $\mathrm{Pt}(\mathrm{CN})_{4}{ }^{2-}$ were estimated for five adsorption-desorption cycles from a mixed metal cyanide complex solution. The results are shown in Figure 11. As shown in Figure 11, the recovery rates of $\mathrm{Pt}(\mathrm{CN})_{4}{ }^{2-}$ for all five cycles were over $92.0 \%$ in the mixture. According to the experimental results, TEBAC-HKUST-1 MOR(N, $1.5 \mathrm{wt} \%$ ) exhibited an efficient separation for $\mathrm{Pt}(\mathrm{CN})_{4}{ }^{2-}$ from a mixed metal cyanide complex solution containing $\mathrm{Pt}(\mathrm{CN})_{4}{ }^{2-}, \mathrm{Co}(\mathrm{CN})_{6}{ }^{3-}, \mathrm{Fe}(\mathrm{CN})_{6}{ }^{3-}$, and $\mathrm{Cu}(\mathrm{CN})_{3}{ }^{2-}$, as well as excellent reusability.

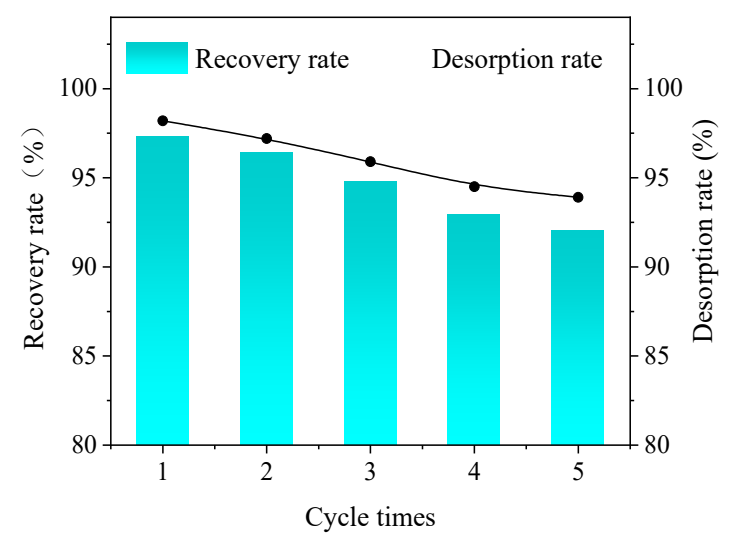

Figure 11. The recovery rates for $\mathrm{Pt}(\mathrm{CN})_{4}{ }^{2-}$ in the mixed solution for five cycles.

\section{Materials and Methods}

\subsection{Materials and Reagents}

Triethylamine, activated carbon (AC), 4-vinylbenzyl chloride (pCMS), and ethanedithiol were purchased from Alfa Aesar (China). $\mathrm{Cu}\left(\mathrm{NO}_{3}\right)_{2} \cdot 3 \mathrm{H}_{2} \mathrm{O}$, benzene tricarboxylic acid (BTC), 2,2'-azobis(2-methylpropionitrile) (AIBN), $\mathrm{K}_{2} \mathrm{Pt}(\mathrm{CN})_{4}, \mathrm{~K}_{3} \mathrm{Co}(\mathrm{CN})_{6}, \mathrm{CuCN}$, and $\mathrm{K}_{3} \mathrm{Fe}(\mathrm{CN})_{6}$ were purchased from Sigma-Aldrich. All other reagents used in this study were commercially available analytical-grade reagents. $\mathrm{Cu}(\mathrm{CN})_{3}{ }^{2-}$ was prepared according to literature report [11]. The metal salts were mixed together in water as needed.

\subsection{Apparatus}

$\mathrm{Pt}(\mathrm{II}), \mathrm{Co}(\mathrm{III}), \mathrm{Cu}(\mathrm{I})$, and Fe(III) concentrations were determined using an ICP-AES instrument (ICAP 6300, Thermo Fisher Scientific, Waltham, MA, USA). The surface area of the adsorbent was measured using a Micromeritics Tristar apparatus (Micromeritics Instrument Corporation, Norcross, GA, USA). Sample morphologies were observed by SEM (FEI Nova NanoSEM 450, Hillsboro, OR, USA). FTIR spectra $\left(400-4000 \mathrm{~cm}^{-1}\right)$ were recorded using a Thermo NICOLET 8700 spectrometer (Thermo Fisher Scientific, Waltham, MA, USA). Thermal properties of samples were investigated by TGA $\left(8-800{ }^{\circ} \mathrm{C}\right)$ under nitrogen using SDT-Q600, USA. The thermogravimetric (TG) curves of samples were obtained using a TG analyzer (TGA, SDT-Q600, TA Instruments, New Castle, DE, USA) at $25-800{ }^{\circ} \mathrm{C}$ under nitrogen. The phase structure and composition of samples were determined by 
XRD (Shimadzu, Japan) in the $2 \theta$ range from $5^{\circ}$ to $50^{\circ}$. Elemental analysis of TEBAC-HKUST- 1 MOR was obtained from an Elementar Vario EL III (Elementar, Langenselbold, Germany).

\subsection{Preparation of TEBAC-HKUST-1 MOR}

Scheme 1 shows the three-step preparation of target MOR. First, HKUST-1 was obtained using a solvothermal method following the literature reports [35]. Subsequently, SH-HKUST-1 was prepared as follows [36]: $1.0 \mathrm{~g}$ HKUST-1 and $0.25 \mathrm{~g}$ ethanedithiol were added into $100 \mathrm{~mL}$ of anhydrous toluene. The reaction mixture was continuously stirred for $24 \mathrm{~h}$ at room temperature. SH-HKUST-1 was washed with absolute ethanol and dried in a vacuum oven at $40{ }^{\circ} \mathrm{C}$ for $8 \mathrm{~h}$. Finally, $1.00 \mathrm{~g}$ of SH-HKUST- 1 was added into a mixture of $30 \mathrm{~mL}$ absolute ethanol, $0.01 \mathrm{~g}$ PVP, and $0.01 \mathrm{~g}$ AIBN. The reaction mixture was continuously stirred for $8 \mathrm{~h}$ at $80^{\circ} \mathrm{C}$. Next, $1 \mathrm{~mL}$ of pCMS solution was added into the mixture. The resulting mixture was heated at $80^{\circ} \mathrm{C}$ for $24 \mathrm{~h}[52,53]$. Then, $5 \mathrm{~mL}$ of triethylamine was added to the mixture and stirred continuously at $85^{\circ} \mathrm{C}$ for $4 \mathrm{~h}[54,55]$. The product was collected by centrifugation and washed with methyl benzene. The target MOR was dried in a vacuum oven at $60{ }^{\circ} \mathrm{C}$ for $12 \mathrm{~h}$. The elemental analysis results revealed that nitrogen element content in TEBAC-HKUST-1 MOR was $1.5 \mathrm{wt} \%$ [56].

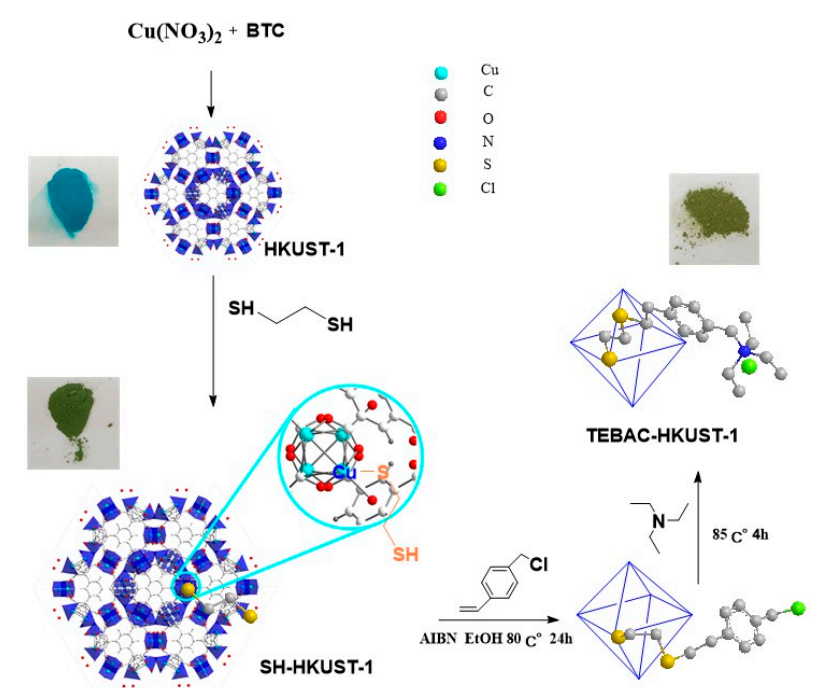

Scheme 1. Preparation of the HKUST-1, SH-HKUST-1 and TEBAC-HKUST-1 MOR.

\section{Conclusions}

A novel functional ion-exchange/adsorption metal organic resin (TEBAC-HKUST-1 MOR) was prepared following a three-step reaction. Owing to the combination of merits of quaternary ammonium ion exchange with the high porosity of matrix structure of HKUST-1 MOFs, TEBAC-HKUST-1 MOR exhibited rapid ion-exchange/adsorption performance for $\mathrm{Pt}(\mathrm{CN})_{4}{ }^{2-}, \mathrm{Co}(\mathrm{CN})_{6}{ }^{3-}, \mathrm{Cu}(\mathrm{CN})_{3}{ }^{2-}$, and $\mathrm{Fe}(\mathrm{CN})_{6}{ }^{3-}$. The maximum experimental adsorption capacities of $\mathrm{Pt}$ (II), $\mathrm{Co}(\mathrm{III}), \mathrm{Cu}(\mathrm{I})$, and $\mathrm{Fe}(\mathrm{III})$ reached 290.0, 101.1, 87.3, and 109.2, respectively. Furthermore, the adsorbed $\mathrm{Pt}(\mathrm{CN})_{4}{ }^{2-}$ could be selectively recovered by two-step elution. First, the loaded $\mathrm{Co}(\mathrm{CN})_{6}{ }^{3-}, \mathrm{Cu}(\mathrm{CN})_{3}{ }^{2-}$, and $\mathrm{Fe}(\mathrm{CN})_{6}{ }^{3-}$ on TEBAC-HKUST-1 MOR could be eluted using a $\mathrm{NaCl}$ solution. Subsequently, $\mathrm{NH}_{4} \mathrm{SCN}$ solution was used to elute the loaded $\mathrm{Pt}(\mathrm{CN})_{4}{ }^{2-}$. TEBAC-HKUST-1 MOR exhibited efficient separation for $\mathrm{Pt}(\mathrm{CN})_{4}{ }^{2-}$ from a mixed metal cyanide complex solution containing $\mathrm{Pt}(\mathrm{CN})_{4}{ }^{2-}, \mathrm{Co}(\mathrm{CN})_{6}{ }^{3-}$, $\mathrm{Fe}(\mathrm{CN})_{6}{ }^{3-}$, and $\mathrm{Cu}(\mathrm{CN})_{3}{ }^{2-}$, as well as excellent reusability. Adsorption isotherms, kinetics models, and adsorption thermodynamics of $\mathrm{Pt}(\mathrm{CN})_{4}{ }^{2-}$ on TEBAC-HKUST-1 MOR were also systematically investigated. TEBAC-HKUST-1 MOR not only exhibited excellent ability for the rapid removal of metal cyanide complexes, but also provided a new idea for the extraction of noble metals from cyanide-contaminated water. 
Author Contributions: Conceptualization, M.C. and Q.Y.; investigation, S.J. and M.S.; data curation, C.J.; writing-original draft preparation, Z.H.

Funding: The authors gratefully acknowledge financial support from National Natural Science Foundation of China (51764051, 51264038), Free exploration fund for academician (2019HA005) and the Key Natural Science Foundation of Kunming (2017-1-S-12305).

Conflicts of Interest: There are no conflicts to declare.

\section{References}

1. Jaszczak, E.; Polkowska, Z.; Narkowicz, S.; Namiesnik, J. Cyanides in the environment-analysis-problems and challenges. Environ. Sci. Pollut. Res. 2017, 24, 15929-15948. [CrossRef] [PubMed]

2. Yang, Y.K.; Tae, J. Acridinium salt based fluorescent and colorimetric chemosensor for the detection of cyanide in water. Org. Lett. 2006, 8, 5721-5723. [CrossRef] [PubMed]

3. Abbasi, S.; Valinezhad, R.; Khani, H. A novel kinetic spectrophotometric method for the determination of ultra trace amount of cyanide. Spectrochim. Acta A 2010, 77, 112-116. [CrossRef] [PubMed]

4. Chen, J.; Huang, K. A new technique for extraction of platinum group metals by pressure cyanidation. Hydrometallurgy 2006, 82, 164-171. [CrossRef]

5. Yu, B.; Li, C.Y.; Sun, Y.X.; Jia, H.R.; Guo, J.Q.; Li, J. A new azine derivative colorimetric and fluorescent dual-channel probe for cyanide detection. Spectrochim. Acta A 2017, 184, 249-254. [CrossRef] [PubMed]

6. Dash, R.R.; Gaur, A.; Balomajumder, C. Cyanide in industrial wastewaters and its removal: A review on biotreatment. J. Hazard. Mater. 2009, 163, 1-11. [CrossRef]

7. Dash, R.R.; Balomajumder, C.; Kumar, A. Treatment of metal cyanide bearing wastewater by simultaneous adsorption and biodegradation (SAB). J. Hazard. Mater. 2008, 152, 387-396. [CrossRef] [PubMed]

8. Yeddou, A.R.; Chergui, S.; Chergui, A.; Halet, F.; Hamza, A.; Nadjemi, B.; Ould-Dris, A.; Belkouch, J. Belkouch, Removal of cyanide in aqueous solution by oxidation with hydrogen peroxide in presence of copper-impregnated activated carbon. Miner. Eng. 2011, 24, 788-793. [CrossRef]

9. Kim, S.J.; Lim, K.H.; Joo, K.H.; Lee, M.J.; Kil, S.G.; Cho, S.Y. Removal of heavy metal-cyanide complexes by ion exchange. Korean J. Chem. Eng. 2002, 19, 1078-1084. [CrossRef]

10. Vidal, L.; Riekkola, M.L.; Canals, A. Ionic liquid-modified materials for solid-phase extraction and separation: A review. Anal. Chim. Acta 2012, 715, 19-41. [CrossRef]

11. Schoeman, E.; Bradshaw, S.M.; Akdogan, G.; Snyders, C.A.; Eksteen, J.J. The extraction of platinum and palladium from a synthetic cyanide heap leach solution with strong base anion exchange resins. Int. J. Miner. Process. 2017, 162, 27-35. [CrossRef]

12. Desai, A.V.; Manna, B.; Karmakar, A.; Sahu, A.; Ghosh, S.K. A water-stable cationic metal-organic framework as a dual adsorbent of oxoanion pollutants. Angew. Chem. Int. Ed. 2016, 55, 7811-7815. [CrossRef] [PubMed]

13. Kumar, P.; Pournara, A.; Kim, K.H.; Bansal, V.; Rapti, S.; Manos, M.J. Metal-organic frameworks: Challenges and opportunities for ion-exchange/sorption applications. Prog. Mater. Sci. 2017, 86, 25-74. [CrossRef]

14. Shi, P.F.; Zhao, B.; Xiong, G.; Hou, Y.L.; Cheng, P. Fast capture and separation of, and luminescent probe for, pollutant chromate using a multi-functional cationic heterometal-organic framework. Chem. Commun. 2012, 48, 8231-8233. [CrossRef] [PubMed]

15. Howarth, A.J.; Katz, M.J.; Wang, T.C.; Platero-Prats, A.E.; Chapman, K.W.; Hupp, J.T.; Farha, O.K. High efficiency adsorption and removal of selenate and selenite from water using metal-organic frameworks. J. Am. Chem. Soc. 2015, 137, 7488-7494. [CrossRef] [PubMed]

16. Lin, K.Y.A.; Chen, S.Y.; Jochems, A.P. Highly selective adsorbents for removal of phosphate from water and urine. Mater. Chem. Phys. 2015, 160, 168-176. [CrossRef]

17. Karmakar, S.; Dechnik, J.; Janiak, C.; De, S. Aluminium fumarate metal-organic framework: A super adsorbent for fluoride from water. J. Hazard. Mater. 2016, 303, 10-20. [CrossRef]

18. Li, T.; Yang, Z.Q.; Zhang, X.P.; Zhu, N.W.; Niu, X.J. Perchlorate removal from aqueous solution with a novel cationic metal-organic frameworks based on amino sulfonic acid ligand linking with $\mathrm{Cu}-4,4^{\prime}$-bipyridyl chains. Chem. Eng. J. 2015, 281, 1008-1016. [CrossRef]

19. Chen, S.S.; Wang, P.; Takamizawa, S.; Okamura, T.; Chen, M.; Sun, W.Y. Zinc(II) and cadmium(II) metal-organic frameworks with 4 -imidazole containing tripodal ligand: Sorption and anion exchange properties. Dalton Trans. 2014, 43, 6012-6020. [CrossRef] 
20. Li, Z.Q.; Yang, J.C.; Sui, K.W.; Yin, N. Facile synthesis of metal-organic framework MOF-808 for arsenic removal. Mater. Lett. 2015, 160, 412-414. [CrossRef]

21. Liu, T.; Che, J.X.; Hu, Y.Z.; Dong, X.W.; Liu, X.Y.; Che, C.M. Alkenyl/thiol-derived metal-organic frameworks (MOFs) by means of postsynthetic modification for effective mercury adsorption. Chem. Eur. J. 2014, 20, 14090-14095. [CrossRef] [PubMed]

22. Luo, X.B.; Ding, L.; Luo, J.M. Adsorptive removal of $\mathrm{Pb}$ (II) ions from aqueous samples with amino-functionalization of metal-organic frameworks MIL-101(Cr). J. Chem. Eng. Data 2015, 60, 1732-1743. [CrossRef]

23. Wang, Y.; Ye, G.Q.; Chen, H.H.; Hu, X.Y.; Niu, Z.; Ma, S.Q. Functionalized metal-organic framework as a new platform for efficient and selective removal of cadmium(II) from aqueous solution. J. Mater. Chem. A 2015, 3, 15292-15298. [CrossRef]

24. Liu, Y.; Huang, Z.J.; Li, J.F.; Chen, J. Solvent extraction of palladium(II) from alkaline cyanide solution by the dodecyl dimethhy-2-phenoxyethyl ammonium bromide. J. Chil. Chem. Soc. 2016, 61, 2864-2869. [CrossRef]

25. Chen, M.H.; Wu, S.J.; Huang, Z.J.; Chen, J.; Chen, M.J. Separation and recovery of Pd(II) and Pt(II) from cyanide liquors of Pd-Pt flotation concentrate via solvent extraction. J. Chem. Technol. Biotechnol. 2017, 92, 1699-1709. [CrossRef]

26. Jiang, J.Z.; Zhou, W.J.; Gao, H.C.; Wu, J.G.; Xu, G.X. Solvent extraction and stripping of gold(I) cyanide in the tetradecyldimethylbenzylammonium chloride system. Hydrometallurgy 2003, 70, 73-81. [CrossRef]

27. Zhang, T.X.; Huang, B.G.; Zhou, W.J.; Gao, H.C.; Chen, J.; Wu, H.S.; Wu, J.G. Extraction and recovery of gold from $\mathrm{KAu}(\mathrm{CN})_{2}$ using cetyltrimethylammonium bromide microemulsions. J. Chem. Technol. Biotechnol. 2001, 76, 1107-1111. [CrossRef]

28. Zhang, Q.; Chen, M.; Zhong, L.; Ye, Q.; Jiang, S.; Huang, Z. Highly effective removal of metal cyanide complexes and recovery of palladium using quaternary-ammonium-functionalized MOFs. Molecules 2018, 23, 2086. [CrossRef]

29. Lin, K.Y.A.; Yang, H.T.; Petit, C.; Hsu, F.K. Removing oil droplets from water using a copper-based metal organic frameworks. Chem. Eng. J. 2014, 249, 293-301. [CrossRef]

30. Azhar, M.R.; Abid, H.R.; Sun, H.Q.; Periasamy, V.; Tade, M.O.; Wang, S. Excellent performance of copper based metal organic framework in adsorptive removal of toxic sulfonamide antibiotics from wastewater. $J$. Colloid Interface Sci. 2016, 478, 344-352. [CrossRef]

31. Maleki, A.; Hayati, B.; Naghizadeh, M.; Joo, S.W. Adsorption of hexavalent chromium by metal organic frameworks from aqueous solution. J. Ind. Eng. Chem. 2015, 28, 211-216. [CrossRef]

32. Ke, F.; Qiu, L.G.; Yuan, Y.P.; Peng, F.M.; Jiang, X.; Xie, A.J.; Shen, Y.H.; Zhu, J.F. Thiol-functionalization of metal-organic framework by a facile coordination-based postsynthetic strategy and enhanced removal of $\mathrm{Hg}^{2+}$ from water. J. Hazard. Mater. 2011, 196, 36-43. [CrossRef]

33. Alemdar, A.; Atici, O.; Güngör, N. The influence of cationic surfactants on rheological properties of bentonite-water systems. Mater. Lett. 2000, 43, 57-61. [CrossRef]

34. Hibble, S.J.; Chippindale, A.M.; Bilbe, E.J.; Marelli, E.; Harris, P.J.F.; Hannon, A.C. Structures of $\operatorname{Pd}(\mathrm{CN})_{2}$ and $\mathrm{Pt}(\mathrm{CN})_{2}$ : Intrinsically Nanocrystalline Materials? Inorg. Chem. 2011, 50, 104-113. [CrossRef]

35. Wee, L.H.; Lohe, M.R.; Janssens, N.; Kaskel, S.; Martens, J.A. Fine tuning of the metal-organic framework $\mathrm{Cu}_{3}(\mathrm{BTC})_{2}$ HKUST-1 crystal size in the $100 \mathrm{~nm}$ to 5 micron range. J. Mater. Chem. 2012, 22, 13742-13746. [CrossRef]

36. Chen, C.; Wu, Z.W.; Que, Y.G.; Li, B.X.; Guo, Q.R.; Li, Z.; Wang, L.; Wan, H.; Guan, G.F. Immobilization of a thiol-functionalized ionic liquid onto HKUST-1 through thiol compounds as the chemical bridge. RSC Adv. 2016, 6, 54119-54128. [CrossRef]

37. Mahmoodi, N.M.; Abdi, J. Nanoporous metal-organic framework (MOF-199): Synthesis, characterization and photocatalytic degradation of Basic Blue 41. Microchem. J. 2019, 144, 436-442. [CrossRef]

38. Abid, H.R.; Pham, G.H.; Ang, H.M.; Tade, M.O.; Wang, S. Adsorption of $\mathrm{CH}_{4}$ and $\mathrm{CO}_{2}$ on $\mathrm{Zr}$-metal organic frameworks. J. Colloid Interface Sci. 2012, 366, 120-124. [CrossRef]

39. Senkovska, I.; Kaskel, S. High pressure methane adsorption in the metal-organic frameworks $\mathrm{Cu}_{3}(\mathrm{btc})_{2}$, $\mathrm{Zn}_{2}$ (bdc) $)_{2}$ dabco, and $\mathrm{Cr}_{3} \mathrm{~F}\left(\mathrm{H}_{2} \mathrm{O}\right)_{2} \mathrm{O}(\mathrm{bdc})_{3}$. Microporous Mesoporous Mater. 2008, 112, 108-115. [CrossRef]

40. Alavi, M.A.; Morsali, A. Synthesis and characterization of different nanostructured copper(II) metal-organic frameworks by a ligand functionalization and modulation method. Crystengcomm 2014, 16, 2246-2250. [CrossRef] 
41. Laiho, T.; Leiro, J.A.; Heinonen, M.H.; Mattila, S.S.; Lukkari, J. Photoelectron spectroscopy study of irradiation damage and metal-sulfur bonds of thiol on silver and copper surfaces. J. Electron Spectrosc. 2005, 142, 105-112. [CrossRef]

42. Muench, F.; Fuchs, A.; Mankel, E.; Rauber, M.; Lauterbach, S.; Kleebe, H.J.; Ensinger, W. Synthesis of nanoparticle/ligand composite thin films by sequential ligand self assembly and surface complex reduction. J. Colloid Interface Sci. 2013, 389, 23-30. [CrossRef] [PubMed]

43. Cao, W.; Wang, Z.Q.; Zeng, Q.L.; Shen, C.H. ${ }^{13}$ C NMR and XPS characterization of anion adsorbent with quaternary ammonium groups prepared from rice straw, corn stalk and sugarcane bagasse. Appl. Surf. Sci. 2016, 389, 404-410. [CrossRef]

44. Beck, M.T.; Bertóti, I.; Mohai, M.; Németh, P.; Jakab, E.; Szabó, L.; Szépvölgyi, J. Gold nano-particle formation from crystalline AuCN: Comparison of thermal, plasma- and ion-beam activated decomposition. J. Solid State Chem. 2017, 246, 65-74. [CrossRef]

45. Azhar, M.R.; Abid, H.R.; Sun, H.; Periasamy, V.; Tade, M.O.; Wang, S. One-pot synthesis of binary metal organic frameworks (HKUST-1 and UiO-66) for enhanced adsorptive removal of water contaminants. J. Colloid Interface Sci. 2017, 490, 685-694. [CrossRef] [PubMed]

46. Lukey, G.C.; van Deventer, J.S.J.; Shallcross, D.C. The effect of functional group structure on the elution of metal cyanide complexes from ion exchange resins. Sep. Sci. Technol. 2000, 35, 2393-2413. [CrossRef]

47. Mpinga, C.N.; Bradshaw, S.M.; Akdogan, G.; Snyders, C.A.; Eksteen, J.J. The extraction of Pt, Pd and Au from an alkaline cyanide simulated heap leachate by granular activated carbon. Miner. Eng. 2014, 55, 11-17. [CrossRef]

48. Snyders, C.A.; Bradshaw, S.M.; Akdogan, G.; Eksteen, J.J. Factors affecting the elution of Pt, Pd and Au cyanide from activated carbon. Miner. Eng. 2015, 80, 14-24. [CrossRef]

49. Taguchi, S.; Takayoshi, K.; Yotsu, Y.; Kasahara, I. Ion-pair solid-phase extraction with membranes: Group contributions and steric effects of ions on the extraction behaviour. Analyst 1996, 121, 1621-1625. [CrossRef]

50. Lin, L.C.; Juang, R.S. Ion-exchange equilibria of $\mathrm{Cu}(\mathrm{II})$ and $\mathrm{Zn}$ (II) from aqueous solutions with Chelex 100 and Amberlite IRC 748 resins. Chem. Eng. J. 2005, 112, 211-218. [CrossRef]

51. Lukey, G.C.; van Deventer, J.S.J.; Shallcross, D.C. Selective elution of copper and iron cyanide complexes from ion exchange resins using saline solutions. Hydrometallurgy 2000, 56, 217-236. [CrossRef]

52. Kumar, P.; Pandey, R.K.; Hegde, V.R. Anti-markovnikov addition of thiols across double bonds catalyzed by H-Rho-zeolite. Synlett 1999, 12, 1921-1922. [CrossRef]

53. Silveira, C.C.; Mendes, S.R.; Líbero, F.M. Solvent-free anti-markovnikov addition of thiols to alkenes using anhydrous cerium(III) chloride as catalyst. Synlett 2010, 2010, 790-792. [CrossRef]

54. Marino, M.G.; Kreuer, K.D. Alkaline stability of quaternary ammonium cations for alkaline fuel cell Membranes and Ionic Liquids. Chemsuschem 2015, 8, 513-523. [CrossRef]

55. Wang, M.L.; Hsieh, Y.M. Kinetic study of dichlorocyclopropanation of 4-vinyl-1-cyclohexene by a novel multisite phase transfer catalyst. J. Mol. Catal. A Chem. 2004, 210, 59-68. [CrossRef]

56. Chen, J.Z.; Li, K.G.; Chen, L.M.; Liu, R.L.; Huang, X.; Ye, D. Conversion of fructose into 5-hydroxymethylfurfural catalyzed by recyclable sulfonic acid-functionalized metal-Organic frameworks. Green Chem. 2014, 16, 2490-2499. [CrossRef]

Sample Availability: Samples of the compounds are not available from the authors. 